\title{
BIBLIOTECÁRIO, COACHING E GESTÃO DO CONHECIMENTO
}

\author{
LIBRARIAN, COACHING AND KNOWLEDGE MANAGEMENT
}

BIBLIOTECARIO, COACHING Y GESTIÓN DEL CONOCIMIENTO

Gildenir Carolino Santos ${ }^{1}$

Universidade Estadual de Campinas - Sistema de Bibliotecas

\section{Correspondência}

${ }^{1}$ Gildenir Carolino Santos

Universidade Estadual de Campinas - Sistema de Bibliotecas

Campinas, SP - Brasil.

E-mail: gilbfe@unicamp.br

ORCID: http://orcid.org/0000-0002-4375-6815

Submetido em: 24-11-2017

Aceito em: 30-11-2017

Publicado em: 26-12-2017

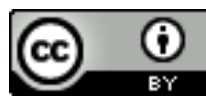

JITA: FJ. Knowledge management 


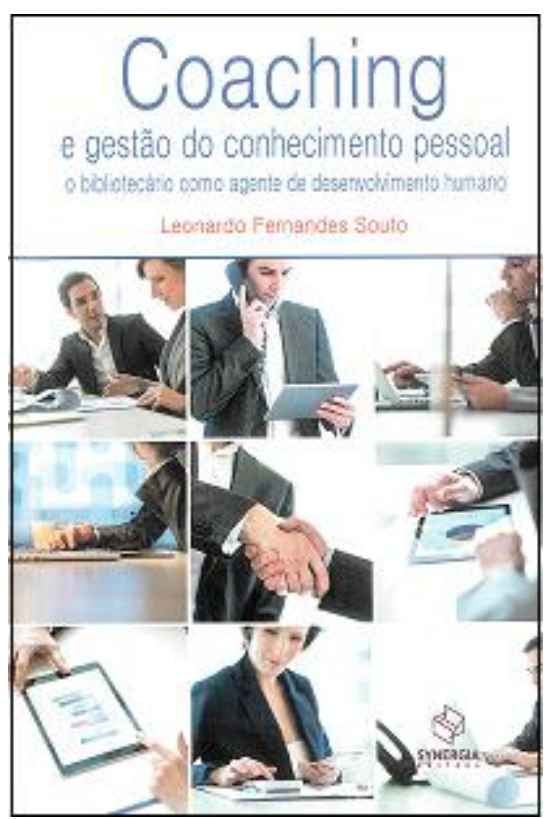

Inicio essa resenha falando do autor. Leonardo Fernandes Souto é doutor em Ciência da Informação pela Universidade de São Paulo (USP) e também mestre em Ciência da Informação pela Pontifícia Universidade Católica de Campinas (PUC-Campinas). Tem bacharelado em Biblioteconomia e Documentação pelo Centro Universitário de Formiga (UNIFOR) e bacharelado em Administração pela Universidade Federal Fluminense (UFF). Como um grande e contínuo estudioso Leonardo, possui ainda certificações em auditória de gestão do conhecimento, programação neurolinguística, master coaching e líder coaching. Além disso, o autor atuou como bibliotecário nas Bibliotecas Centrais da Universidade de Uberaba e da Universidade Estadual de Campinas (UNICAMP), onde também atuou como um dos co-editores da RDBCI: Revista Digital de Biblioteconomia e Ciência da Informação de 2003 a 2006, sendo atualmente parecerista ad hoc dessa publicação. Atuou também na gerência de Gestão de Conhecimento da Universidade Petrobras, e no Centro de Pesquisa de Informações e Dados (COPED) e Gerência de Editoração e Memória do Banco Nacional de Desenvolvimento Econômico e Social (BNDES). Atualmente trabalha na Gerência de Processos do Departamento de Segurança da Informação e Processos, da Área de Gestão de Riscos do Banco Nacional de Desenvolvimento Econômico e Social (BNDES).

"...Esta obra de Leonardo Fernandes Souto inicia-se tratando dos meios pelos quais se faz a Gestão do Conhecimento Pessoal, ou seja, como se planeja, organiza, mobiliza e controla os resultados do seu próprio conhecimento pessoal desenvolvido, mas já se pode supor, a partir das considerações de Polanyi (1958), que esta tanto é melhor quanto mais se evolui no desenvolver da consciência e da apreensão da realidade, do indivíduo encontrar e saber trilhar os caminhos com os quais defronta-se em seu cotidiano. E aí entram técnicas como o coaching, descritas no livro. Ou seja, o coaching torna-se de imensa valia para a gestão do conhecimento pessoal do indivíduo, seja aplicado às organizações, a outros ambientes, enfim, à sua própria vida. $\mathrm{O}$ coaching faz valer também a importância da relação com o outro, no sentido de estimular o indivíduo na busca do seu caminho. O livro é 
fortemente recomendado, especialmente para os bibliotecários, mas também para qualquer outro profissional interessado em buscar respostas para o seu desenvolvimento pessoal..."

De acordo com a Sociedade Latino Americana de Coaching (SLAC),

O coaching é uma palavra em inglês que define um processo de desenvolvimento humano, pautado em diversas ciências e técnicas para auxiliar as pessoas e empresas no alcance de metas, no desenvolvimento acelerado e, em sua evolução contínua.

Há diversas teorias sobre a origem do termo coach no contexto do desenvolvimento de pessoas, mas, em algum lugar da história, ele compartilha um ancestral comum com o verbo em inglês "coax", que significa PERSUADIR.

O profissional de coaching atua como um ESTIMULADOR externo que desperta o potencial interno de outras pessoas, usando uma combinação de flexibilidade, insight, perseverança, estratégias, ferramentas pautadas em uma metodologia de eficácia comprovada e, então, o Coach (Profissional) acompanha seu Coachee (Cliente), demonstrando interesse genuíno (às vezes chamado de carisma) para APOIAR os seus clientes de Coaching (Coachees) a acessar seus recursos internos e externos e, com isso, melhorar seu desempenho. Além dessa definição, há outras interpretações sobre a função, o comportamento e as características de um coach.

Dependendo das circunstâncias, é possível que o coach precise adotar estilos muito diferentes a fim de atender às necessidades de seus coachees. Entre os fatores que podem influenciar na abordagem de coaching estão a complexidade da meta, os riscos de erro na realização da tarefa, o nível inicial de disponibilidade para o coaching por partes dos integrantes da equipe, sua autoconfiança e capacitação para a tarefa e o nível de maturidade para a aprendizagem demonstrado pelo coachee (até que ponto ele se mostra capaz de cogerenciar o processo de coaching). ${ }^{1}$

A obra está estruturada em sete capítulos sendo que o Capítulo 1 é a Introdução. No Capítulo 2, o autor disserta sobre a "Gestão do Conhecimento Pessoal e Desenvolvimento Humano" fazendo um entrelace com uma revisão de literatura. Na sequência do Capítulo 3, intitulado "Compreendendo o Coaching", o autor relata sobre a origem, estilos e abordagens sobre o coaching amparado com base na revisão de literatura. No Capítulo 4, o autor fala sobre a "Biblioteconomia e Coaching" em que são apresentadas as funções das bibliotecas e competências dos bibliotecários. No Capítulo 5 sob a titulação "Coaching Educacional", o autor aponta experiências e perspectivas sobre o coaching. No Capítulo 6 - "Planejamento do Núcleo de Orientação Educacional em Bibliotecas", o autor auxilia na elaboração do projeto e as ferramentas de apoio que o constitui.

No último capítulo, ou seja, o Capítulo 7, o autor finaliza com as "Considerações Finais" contextualizando o fechamento da obra dizendo que:

[...] despertar o interesse do bibliotecário para a implantação de um processo sistematizado e legitimado de coaching é uma forma para expandir a visão da sociedade quanto ao papel e valor deste profissional, normalmente, reconhecido por suas capacidades técnicas, e, mais notoriamente, por aquelas relacionadas à aquisição, organização, guarda e empréstimos de documentos. É, ainda, uma forma de colocar em evidência sua formação e suas competências de gestor do conhecimento, além de gestor da informação, permitindo-lhe atuar no âmbito do desenvolvimento pessoal e do autoconhecimento. (SOUTO, 2017, p.59).

\footnotetext{
${ }^{1}$ Fonte: O que é coaching. Disponível em: 〈https://www.slacoaching.com.br/o-que-e-coaching >.
}

\begin{tabular}{|c|c|c|c|c|c|}
\hline (C) RDBCI: Rev. Digit. Bibliotecon. Cienc. Inf. & Campinas, SP & v.16 & n.1 & p.260-263 & jan./abr. 2018 \\
\hline
\end{tabular}


Sendo afim, finalizamos dizendo que o coaching é o caminho ideal para as pessoas se tornarem mais produtivas, por intermédio de metodologias que abordam diversos aspectos como visão e missão pessoal e da organização, descoberta pessoal e realização do potencial, inclusive o profissional bibliotecário. Além disso, o coaching alinhado à gestão do conhecimento pessoal tem tudo para dar certo para as soluções de problemas enfrentados pelo bibliotecário que tem espírito de liderança e sabe gerenciar seus conflitos e as ações do seu dia-a-dia.

A obra é direcionada para estudantes de biblioteconomia, administração e áreas afins, bem como para profissionais da informação e gestores de bibliotecas e centros de informação e pesquisa.

\section{Referências}

SOUTO, Leonardo Fernandes. Coaching e gestão do conhecimento pessoal: o bibliotecário como agente do desenvolvimento humano. Rio de Janeiro: Synergia, 2017. 96 p. ISBN: 97885-68483-51-0. 